\title{
Seasonal prediction of global sea level anomalies using an ocean-atmosphere dynamical model
}

\author{
Elaine R. Miles • Claire M. Spillman • \\ John A. Church $\cdot$ Peter C. McIntosh
}

Received: 19 June 2013/Accepted: 24 December 2013/Published online: 12 February 2014

(C) The Author(s) 2014. This article is published with open access at Springerlink.com

\begin{abstract}
Advanced warning of extreme sea level events is an invaluable tool for coastal communities, allowing the implementation of management policies and strategies to minimise loss of life and infrastructure damage. This study is an initial attempt to apply a dynamical coupled oceanatmosphere model to the prediction of seasonal sea level anomalies (SLA) globally for up to 7 months in advance. We assess the ability of the Australian Bureau of Meteorology's operational seasonal dynamical forecast system, the Predictive Ocean Atmosphere Model for Australia (POAMA), to predict seasonal SLA, using gridded satellite altimeter observation-based analyses over the period 1993-2010 and model reanalysis over 1981-2010. Hindcasts from POAMA are based on a 33-member ensemble of seasonal forecasts that are initialised once per month for the period 1981-2010. Our results show POAMA demonstrates high skill in the equatorial Pacific basin and consistently exhibits more skill globally than a forecast based on persistence. Model predictability estimates indicate there is scope for improvement in the higher latitudes and in the Atlantic and Southern Oceans. Most characteristics of the asymmetric SLA fields generated by ElNino/La Nina events are well represented by POAMA, although the forecast amplitude weakens with increasing lead-time.
\end{abstract}

E. R. Miles $(\square) \cdot$ C. M. Spillman

Centre for Australian Weather and Climate Research (CAWCR), Bureau of Meteorology, GPO Box 1289, Melbourne, VIC 3001, Australia

e-mail: e.miles@bom.gov.au

J. A. Church - P. C. McIntosh

Centre for Australian Weather and Climate Research (CAWCR),

CSIRO Marine and Atmospheric Research,

GPO Box 1538, Hobart, TAS 7001, Australia
Keywords Seasonal forecasting - Climate variability . Climate change $\cdot$ Sea level $\cdot$ POAMA

\section{Introduction}

Sea level rise is expected to be one of the most profound consequences of climate change and has been identified by the Intergovernmental Panel on Climate Change (IPCC) as a serious problem threatening a large percentage of the earth's coasts, atolls, estuaries and river deltas (Nicholls et al. 2007; McGranahan et al. 2007). Global mean sea level rise, due to rising ocean temperatures and mass loss from glaciers and ice sheets, is currently estimated as $3.2 \pm 0.4 \mathrm{~mm} \mathrm{year}^{-1}$ over 1993-2012 (Church and White 2011) and is projected to accelerate under climate change. Changes in mean sea level will influence the frequency and impact of extreme sea level events. Higher mean sea level will result in sea level variations exceeding thresholds more frequently, an outcome that has already been observed at many locations (Church et al. 2006a; McInnes et al. 2009; Menendez et al. 2009).

In addition to the input from the increasing global trend, extreme sea level events are influenced by changes in mean sea level associated with intra-seasonal to interannual climate processes such as the El Niño/Southern Oscillation (ENSO), the Indian Ocean Dipole (IOD), the Southern Annular Mode (SAM) and the Madden-Julian Oscillation (MJO). These sea level signals have significant amplitudes, can persist for many months and have the capability to exacerbate extreme sea levels from spring tides and/or storm surges. The impacts of extreme sea levels include: the loss of amenities; the inhibition of primary production processes; loss of property, cultural resources and values; loss of tourism, recreation and transportation functionality; and increased risk of loss of life (Nicholls et al. 2007). 
Seasonal sea level variability, both temporal and spatial, is a result of large scale changes in the baroclinic and barotropic ocean circulation (associated with changes in the wind and ocean density fields), the average ocean density and barystatic changes (changes in mass) in the ocean (Gregory et al. 2013). Table 1 shows the key contributors to seasonal sea level variability and their measured impact on both global and regional sea level. On both a global and regional scale, the dominant seasonal variability contribution comes from ENSO, which can create coherent changes of up to $20-30 \mathrm{~cm}$ within regions of the Pacific Ocean (Becker et al. 2012), and a net change to mean global sea level of up to about $2 \mathrm{~cm}$ (Nerem et al. 1999). Past studies have found that the interannual variability in global mean sea level due to steric sources was smaller than that from the mass component (Chambers et al. 2004; Lombard et al. 2007; Willis et al. 2008) and that the steric contributions are dominated by ENSO, Pacific Decadal Oscillation (PDO) and the North Atlantic Oscillation (NOA) (Lombard et al. 2005). Further research and more observations are required to precisely calculate the contributions of some processes. Regional sea level variability at the interannual timescale is dominated by ocean variability which locally is much larger than the variability of global mean sea level change over the same time scale. Thus extreme sea level predictions require accurate knowledge of regional interannual sea level variability.

Currently, short-term predictions of sea level are available operationally on weather timescales of a few days, and projections are available for climate change timescales of decades to centuries. For example, nowcast systems use Oceanic General Circulation Models (OGCM) to predict sea level up to 10 days ahead, e.g. the Bureau's BLUElink
OceanMAPs (Brassington et al. 2012) and the French government's Mercator-Ocean (Drévillon et al. 2008). For the climate change timescale, coupled Atmosphere-Ocean General Circulation Models (AOGCMs) have been used to investigate sea level rise and associated extreme events over several decades (Church et al. 2014). However, despite a strong case for seasonal predictions of sea level, few are available. The Pacific ENSO Applications Climate (PEAC) Centre at the National Oceanographic and Atmospheric Administration (NOAA) uses a statistical model that employs tide-gauge measurements of relative sea level to calculate site-specific seasonal sea level outlooks (Chowdhury et al. 2007). Statistical models create forecasts based on historical lagged relationships. Whilst these models have good skill, they are limited to locations with historical sea level records and are likely to be surpassed by dynamical models when there are unprecedented changes to physical forcing and the background climate due to climate change. Dynamical models estimate the future state by numerically integrating the relevant physical and dynamical equations forward in time from the observed current state and provide estimates for the global ocean. Such models are generally better equipped to represent behaviour that is close to or exceeds that previously observed. Thus, creating dynamical seasonal SLA forecasts will contribute to closing the current gap in predicting all of the major components influencing regional sea level.

We have created seasonal forecasts of SLA as part of the Pacific Australia Climate Change Science and Adaptation Program (PACCSAP), funded by AusAID and the Department of Climate Change and Energy Efficiency. As the low-lying island nations in the western Pacific are particularly susceptible to seasonal sea level changes associated mainly with ENSO the primary objective of this

Table 1 Key contributors to seasonal and decadal variations in sea level

\begin{tabular}{|c|c|c|c|c|}
\hline Variety & Periodic source & Operating time scale & $\begin{array}{l}\text { Global vertical } \\
\text { effect }(\mathrm{cm})\end{array}$ & $\begin{array}{l}\text { Regional vertical } \\
\text { effect }(\mathrm{cm})\end{array}$ \\
\hline \multirow{5}{*}{$\begin{array}{l}\text { Meteorological and } \\
\text { oceanographic } \\
\text { processes }\end{array}$} & Inverted barometer (IB) effect & Hours to months & To be established & 7 (Ponte 2006) \\
\hline & ENSO & 6 months every $5-10$ years & $\begin{array}{l}\text { 0.5-2 (Chen et al. 1998; } \\
\text { Boening et al. 2012) }\end{array}$ & $\begin{array}{l}\text { 20-30 (Becker } \\
\text { et al. 2012) }\end{array}$ \\
\hline & SAM & Days to weeks every few months & To be established & To be established \\
\hline & IOD & 6 months every $5-10$ years & To be established & To be established \\
\hline & Water Vapour & 6 months & 0.2 (Landerer et al. 2008) & To be established \\
\hline \multirow[t]{2}{*}{$\begin{array}{l}\text { Seasonal } \\
\text { variations }\end{array}$} & $\begin{array}{l}\text { Seasonal water steric changes } \\
\text { (temperature and salinity) }\end{array}$ & 6 months & 0.37 (Willis et al. 2008) & To be established \\
\hline & $\begin{array}{l}\text { Seasonal water balance } \\
\text { among oceans (mass) }\end{array}$ & 6 months & $\begin{array}{l}\text { 0.6-0.8 (Chambers et al. 2004; } \\
\text { Lombard et al. 2007; } \\
\text { Willis et al. 2008) }\end{array}$ & To be established \\
\hline Gravity & Seasonal Tide (Sa and Ssa) & $6-12$ months & N/A & 0.6-5 (Webb 1988) \\
\hline
\end{tabular}


study is to assess the potential to predict seasonal sea level anomalies. This is done using the Australian Bureau of Meteorology's dynamical coupled ocean-atmosphere multi-model ensemble seasonal system, the Predictive Ocean Atmosphere Model for Australia (POAMA). This study is an initial attempt (the first to our knowledge) to create and quantitatively evaluate large-scale dynamical sea level forecasts over the globe at the seasonal timescale and is a fundamental step towards the creation of seasonal sea level predictions for coastal communities. Accurate seasonal SLA forecasts will be an invaluable tool for the future management and conservation of coastal communities impacted by climate change (Miles et al. 2013; Spillman et al. 2013). Advance warning of probable high sea level events weeks to months in advance allows for the implementation of management strategies to minimise coastal and infrastructure damage.

\section{Methods}

\subsection{The POAMA forecast system}

POAMA is a global coupled ocean-atmosphere ensemble seasonal prediction system, developed jointly by the Australian Bureau of Meteorology and the Commonwealth Scientific and Industrial Research Organisation (CSIRO) Division of Marine and Atmospheric Research (CMAR). POAMA produces intraseasonal-to-seasonal predictions of the Australian climate and has been running operationally at the Bureau of Meteorology since October 2002 (Wang et al. 2008; Hudson et al. 2013).

POAMA consists of a coupled ocean-atmosphere model, a data assimilation system for the initialisation of the ocean, land and atmosphere components, and an ensemble generation procedure to capture forecast uncertainty. This study assesses forecasts from the most recent version of POAMA (version 2). Full details of the modelling system are provided in Hudson et al. (2013; system $\mathrm{P} 2-\mathrm{M}$ in their paper), but an overview is provided below.

\subsubsection{Dynamical models}

The atmospheric model is the Bureau of Meteorology's Atmospheric Model version 3.0 (BAM3.0; Colman et al. 2005; Wang et al. 2005; Zhong et al. 2006) which has a horizontal spectral resolution of T47 (approximately $250 \mathrm{~km}$ grid) and 17 vertical levels. The land-surface component of BAM3.0 is a simple bucket model for soil moisture (Manabe and Holloway 1975) with three soil levels for temperature. The ocean model is the CMAR Australian Community Ocean Model version 2 (ACOM2; Schiller et al. 2002), which is based on the Geophysical
Fluid Dynamics Laboratory Modular Ocean Model version 2.0 (MOM2; Pacanowski 1996). The ocean model grid spacing is $2^{\circ}$ in the zonal direction, and approximately $0.5^{\circ}$ at the equator which gradually increases to $1.5^{\circ}$ at the poles in the meridional direction. It has 25 vertical levels, of which the first 12 levels are in the upper $185 \mathrm{~m}$, and a maximum depth of $5 \mathrm{~km}$. This version of the model includes the hybrid mixed layer model (Chen et al. 1994) and has a time step of $90 \mathrm{~min}$. The coupling of the ocean and atmosphere models is achieved every $3 \mathrm{~h}$ using the Ocean Atmosphere Sea Ice Soil version 3 (OASIS3) coupling software (Valcke et al. 2000).

\subsubsection{Data assimilation}

Forecasts are initialised from observed atmospheric and ocean states. Land-surface and atmospheric initial conditions are created by the Atmosphere-Land Initialization scheme (ALI; Hudson et al. 2010). ALI creates a set of realistic atmospheric states by nudging winds, temperature and humidity from the atmospheric model of POAMA [run prior to the forecasts being made and forced with observed sea surface temperatures (SST)] towards observationally based analyses; the 40-year European Centre for MediumRange Weather Forecasts (ECMWF) Re-Analysis (ERA40; Uppala et al. 2005) for the period 1980 to August 2002 and the Bureau of Meteorology's operational global numerical weather prediction system thereafter. The landsurface is initialised indirectly via the nudged atmosphere (Hudson et al. 2010).

Ocean initial conditions are generated by the POAMA Ensemble Ocean Data Assimilation System (PEODAS; Yin et al. 2011). PEODAS uses an approximate ensemble Kalman filter system which utilises covariances from a time evolving model ensemble (Oke et al. 2005). PEODAS yields an ensemble of initial states, including a central unperturbed ocean analysis, which are intended to span the actual uncertainty in the estimate of the initial conditions. PEODAS assimilates in situ temperature and salinity observations including those from expendable bathythermographs (XBTs), ARGO floats and Tropical Atmosphere Ocean (TAO)/Triangle Trans-Ocean Buoy Network (TRITON)/Prediction and Research Moored Array in the Atlantic (PIRATA) moorings, in addition to satellite SST (Reynolds et al. 2002).

\subsubsection{Ensemble generation}

An ensemble gives an indication of forecast uncertainty. To address model uncertainty, POAMA uses a pseudo multimodel ensemble strategy using three different model configurations of the atmospheric model (Wang et al. 2011; Hudson et al. 2013). 
Perturbations are applied to the atmosphere and ocean at the initial time from a coupled-model breeding technique (Hudson et al. 2013). This aims to sample uncertainty due to initial condition errors. A 33 member ensemble is generated for each forecast case (all initial conditions are valid for the same date and time, i.e. there are no lagged initial conditions). The 33 member ensemble comprises of an 11 member ensemble from each of the three model versions (Hudson et al. 2013).

Retrospective forecasts (hindcasts) are generated on the first of each month for the years 1981-2010, and run forward in forecast mode for 9 months. Forecast skill is assessed using anomalies calculated from hindcast climatology. This is standard practice in seasonal forecasting. The anomalies are created using a lead-time dependent ensemble mean climatology from the hindcasts. The climatology is a function of both lead-time and start date, and thus a first order correction for model mean bias is made (Stockdale 1997). Lead-time is defined as the time elapsed between the model start date and the forecast date, i.e. if the model start date is 1 January, for forecasts for January, February, March and April the lead is written as 0, 1, 2 and 3 months, respectively. Generally, forecast accuracy is highest for lead-time 0 months and decays as forecasts predict further into the future (i.e. increasing lead-time).

To calculate a three monthly (seasonal) average forecast in the model, the forecasts are averaged according to leadtime. For example, the forecast for the January, February and March (JFM) season at lead-time 0 months is the average of January, February and March for the forecasts starting 1 January. For a JFM forecast at a lead-time of 1 month, January, February and March are averaged for forecasts starting on 1 December.

\subsubsection{Ocean model sea level}

It should be noted that ACOM2, used by both POAMA and PEODAS, does not explicitly represent sea level. Instead it returns a model diagnostic described as diagnostic surface height (Pacanowski 1996). ACOM2 uses a rigid-lid approximation which conserves volume (Bryan 1969), and the surface height variations for each grid cell are determined by using the equations of motion to determine the horizontal pressure gradients (and therefore surface height) consistent with the simulated ocean currents. The surface height reflects sea level contributions from the baroclinic and barotropic circulation, and dissipation processes. The following secondary contributors to seasonal sea level variations are not directly simulated: global average thermosteric changes (including the seasonal global mean sea level signal), changes in ocean mass from changes in glacier and ice-sheet mass and changes in land water storage. Additional to this list the following regional effects are not modelled: atmospheric pressure effects, tectonic uplift, selfattraction and loading, glacial isostatic adjustment (GIA), astronomical tides, surface waves, and mesoscale eddies.

\subsection{Altimeter observations}

Gridded observation-based analyses used in this study were generated using sea surface height ( $\mathrm{SSH}$ ) data collected by the Ocean Topography Experiment (TOPEX)/Poseidon, Jason-1 and Jason-2/Ocean Surface Topography Mission (OSTM) satellites. TOPEX/Poseidon and Jason-1 data were obtained from the National Aeronautics and Space Administration (NASA) Physical Oceanography Distributed Active Archive Center at the Jet Propulsion Laboratory/California Institute of Technology. The Jason-2/ OSTM data were obtained from Aviso (Centre National d'Études Spatiales and Collecte Localisation Satellites, France). These observations have been corrected and regridded to a $1^{\circ} \times 1^{\circ}$ grid extending from $65^{\circ} \mathrm{S}$ to $65^{\circ} \mathrm{N}$ and begin in January 1993 (http://www.cmar.csiro.au/sealevel/ sl_data_cmar.html).

All recommended standard corrections (Benada 1997), with the exception of the "standard" inverted barometer (IB) correction which accounts for variations in SSH due to atmospheric pressure changes, were first applied to the altimeter observations. Corrections were also applied for the long-term, spatially uniform $\sim 5 \mathrm{~mm}$ drift in the water vapour path delay (Keihm et al. 2000) and an estimated offset of $\sim 10 \mathrm{~mm}$ caused by equipment replacement (Mitchum 1998; Mitchum 2000; Church et al. 2006b).

Three additional corrections, calculated independently of the standard corrections, are applied in this study to the altimeter observations to remove sea level contributions that POAMA does not simulate: (a) an IB correction; (b) a GIA correction (Church et al. 2006b) and (c) a global sea level trend (GT). The custom IB correction minimises noise in the large-scale variability of the altimeter dataset due to atmospheric pressure variations and is a non-tidal highfrequency dealiasing correction (Church et al. 2004; Ponte 2006). This correction is calculated using atmospheric pressure data from the NCEP-NCAR 50 year reanalysis (Kistler et al. 2001), but adjusted such that the integral of the pressure over the global oceans remains constant, to ensure that no artificial signal in global mean sea level is introduced. This correction assumes the sea level responds isostatically to local changes in atmospheric pressure relative to the global ocean mean (Minster et al. 1999). The GIA correction compensates for changes to the ocean basin shape and gravity caused by surface loading from the melting of large ice sheets from the most recent glaciation (Mitrovica et al. 2001). Lastly, the global trend is removed from the altimeter observations as this configuration of ACOM 2 conserves volume. Note that corrections for solar 
semi-annual and annual tides and land water storage are not removed but these are expected to have a minimal impact on monthly-averaged data.

To facilitate spatial validation, the altimeter observations were regridded to the ocean model grid using an interpolation method that preserves the area-weighted mean.

\subsection{PEODAS reanalysis}

In order to extend the validation period to 1981-2010, the PEODAS ocean assimilation analysis used to initialise the forecast system is used as the primary validation reanalysis dataset. To a certain extent, this amounts to testing the model against itself. However, because PEODAS is the result of a daily data assimilation process, it is substantially constrained where the observational density is high, which reduces model-specific biases and errors. Furthermore, the observations assimilated are of ocean temperature and salinity, and are therefore independent from the altimeter data. Therefore the PEODAS analysis provides a longer and independent validation data set for the forecast system, with the caveat that the skill may be somewhat over-estimated due to interpolating the data using the forecast model. In regions where the data does not constrain the PEODAS analysis tightly, such as the Southern Ocean, we will see that the skill is over-estimated.

To gain confidence in the use of the PEODAS assimilation, we compare it to the altimeter observations over the period 1993-2011 to test if the salient features of seasonal SLA are captured.

\subsection{Model skill}

Several measures were used to assess the performance and skill of POAMA seasonal SLA predictions relative to the PEODAS reanalysis. First, correlations between the monthly model SLA ensemble mean values with observed SLA values in both space and time are calculated using the Pearson correlation coefficient (r). Significance at the $95 \%$ confidence level is determined at each grid point using a two-tailed Student's $t$ test. The number of degrees of freedom is calculated from the length of the time series divided by the lag required for the autocorrelation of the reanalysis to go to zero. Second, Empirical Orthogonal Functions (EOFs) are used to assess the seasonal spatial modes of variability within POAMA (Wilks 1995). Third, the ability of POAMA to accurately capture ENSO events over the entire hindcast period is investigated using composites of mature ENSO events. A time series of SST anomalies (SSTA) from the PEODAS reanalysis was created by averaging over the NINO3 index region $\left(90^{\circ} \mathrm{W}-150^{\circ} \mathrm{W}\right.$ and $\left.5^{\circ} \mathrm{S}-5^{\circ} \mathrm{N}\right)$. The mature ENSO phase is defined in this paper as three or more
Table 2 Periods used for El Niño and La Niña composites

\begin{tabular}{lllll}
\hline El Niño & & & La Niña & \\
\cline { 1 - 2 } \cline { 5 - 6 } Period & $\begin{array}{l}\text { NINO3 } \\
\text { SSTA }\left({ }^{\circ} \mathrm{C}\right)\end{array}$ & & Period & $\begin{array}{l}\text { NINO3 } \\
\text { SSTA }\left({ }^{\circ} \mathrm{C}\right)\end{array}$ \\
\hline $1982.11-1983.01$ & 3.06 & & $1984.12-1985.02$ & -1.26 \\
$1987.07-1987.09$ & 1.58 & & $1988.10-1988.12$ & -1.97 \\
$1991.12-1992.02$ & 1.39 & & $1998.10-1998.12$ & -1.20 \\
$1997.10-1997.12$ & 3.50 & & $1999.11-1901.02$ & -1.65 \\
$2002.09-2002.11$ & 1.23 & & $2007.10-2007.12$ & -1.67 \\
$2009.11-2010.01$ & 1.26 & & $2010.10-2010.12$ & -1.66 \\
\hline
\end{tabular}

consecutive seasons where this NINO3 index has amplitude $>0.8^{\circ} \mathrm{C}$, which is a threshold for onset of ENSO used for operational forecasts in the Australian Bureau of Meteorology. From this time series the six strongest El Niño and La Niño periods are identified (Table 2).

POAMA predictions are also compared with a persistence forecast, from which the baseline skill level in this study is calculated. Persistence forecasts are constructed using the previous monthly anomaly (e.g. the persistence seasonal forecast of SLA starting in April is the March SLA from the reanalysis). Persistence forecasts have value because oceanic and atmospheric variables often exhibit a statistical dependence with their own past values (Wilks 1995) and they represent an economical forecast system (Troccoli et al. 2008). Persistence forecasts are correlated with reanalysis values in the same manner as the model forecasts in order to compare relative skill.

Prediction skill can never be perfect due to the chaotic component in the climate system. The upper limit of possible model skill can be estimated from the spread of the ensemble members. By assuming that the model is perfect, each ensemble member can be considered as a valid forecast of the future ocean state with any differences between it and the remaining ensemble members due to chaos (Griffies and Bryan 1997). Thus, the upper limit of predictability of a model is determined using the spread of the remaining forecasts compared to this future state. Specifically, at each location each member from a particular model configuration is correlated in time with the mean of the remaining ensemble members. The predictability correlations for each of the three sub-models are then averaged to create the multi-model predictability skill.

\section{Results}

\subsection{Observation comparison}

Figure 1 shows the seasonal anomaly correlations of gridded altimeter observations with the PEODAS 
Fig. 1 Correlation of seasonal SLA from January 1993 to December 2011 between the reanalysis and altimeter observations with a no correction applied and $\mathbf{b}$ with IB, GT and GIA corrections applied. The contours show correlations of \pm 0.9 and \pm 0.5 . Significant correlations are shaded ( $|r|>0.456$ is significant at the $95 \%$ confidence level; two tailed $\mathrm{t}$ test, $\mathrm{n}=19$, degrees of freedom determined by autocorrelation) (a)

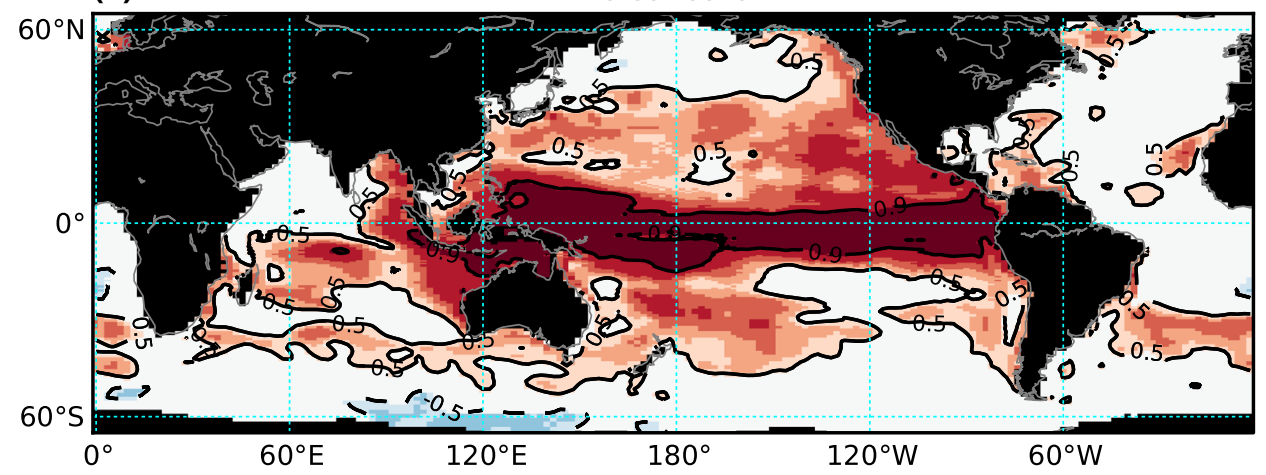

(b)

IB Correction, GIA Correction, Global Trend Removed

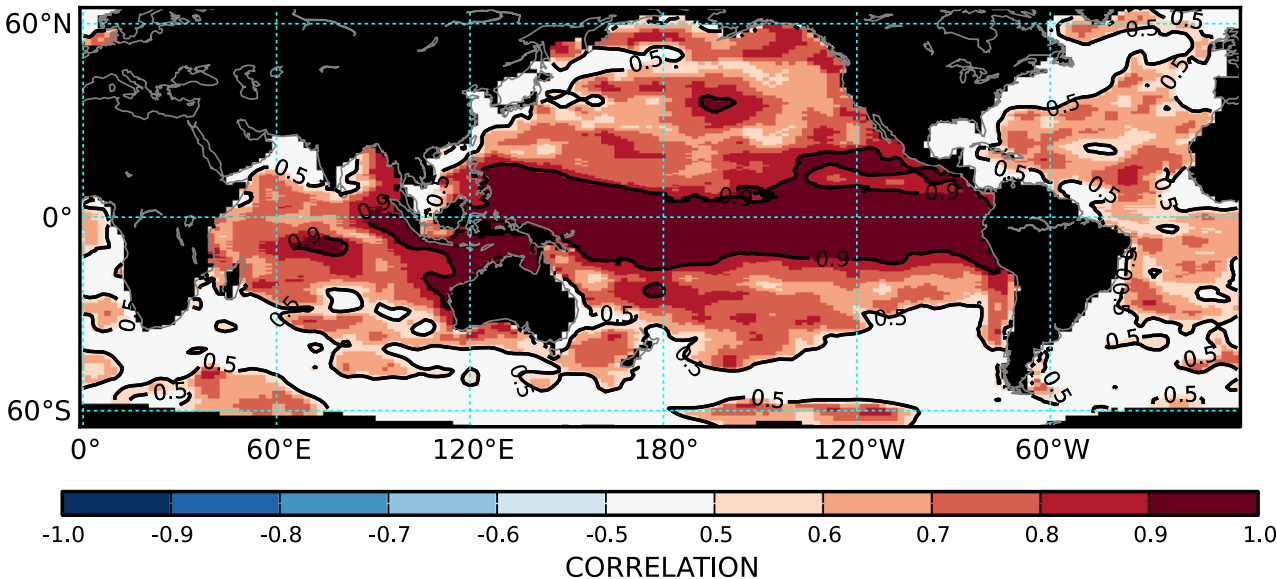

reanalysis from January 1993-December 2011. The first panel shows the correlation when no corrections are applied to the altimeter data, while the second panel shows the increased correlation when the IB, GIA and GT corrections are applied. Remember that the PEODAS reanalysis does not assimilate altimeter measurements, so that the observations and reanalysis are independent.

The reanalysis shows excellent correlation with the uncorrected observations in the equatorial region of the Pacific Ocean $(r>0.9)$, moderate agreement in the Indian Ocean and low agreement in the Atlantic (Fig. 1a). Despite these variations, all of the ocean basins have regions of significant correlation at the $95 \%$ confidence level. The corrected observation dataset increases the correlation in the extratropics, the Atlantic Ocean and the Indian Ocean (Fig. 1b). When looking at the skill for different seasons, there is negligible change in the spatial distribution beyond a slight decrease in skill in the equatorial Pacific and northern Indian Ocean during the boreal summer period (not shown).

Figure 2 shows the standard deviation of SLA over the period January 1993-December 2011 for the reanalysis (Fig. 2a), the corrected observations (Fig. 2b), and the difference between the two (Fig. 2c). The regional variability captured by the reanalysis is in good agreement with the corrected observations with the exception of the Southern Ocean and northern Atlantic Ocean. In the tropics, the largest observed variability, peaking at about $10 \mathrm{~cm}$, occurs in the equatorial Pacific east of the dateline, the two low latitude western boundary current regions of the Pacific, the eastern equatorial Indian Ocean, and in a band across the Indian Ocean just south of the equator. This variability is reproduced well by the reanalysis. In much of the rest of the ocean, the large-scale variability is $<3 \mathrm{~cm}$, and the reanalysis and observations differ by $<1 \mathrm{~cm}$.

Compared to the altimeter data, the reanalysis has a higher variability (maximum $13 \mathrm{~cm}$ ) in the Southern Ocean and northern Atlantic. This is primarily caused by a large change in the analysis due to the availability of many more observations when ARGO floats were introduced in the early years of the twenty-first century. This effect is most noticeable in regions where the model bias is large when not constrained by observations, and is a common problem for ocean data assimilation systems (Yin et al. 2011).

The high skill, comparable variability and large areas of significant correlation support the use of the reanalysis as a verification dataset for the POAMA forecasts over the extended period of 1981-2010. However, there are two caveats: as the climatology only covers 1993-2011, it does not adequately resolve the effects of lower frequency 
Fig. 2 Standard deviation of seasonal SLA from January 1993 to December 2011 for a Reanalysis, b corrected altimeter observations. c The difference of (b) subtracted from (a)

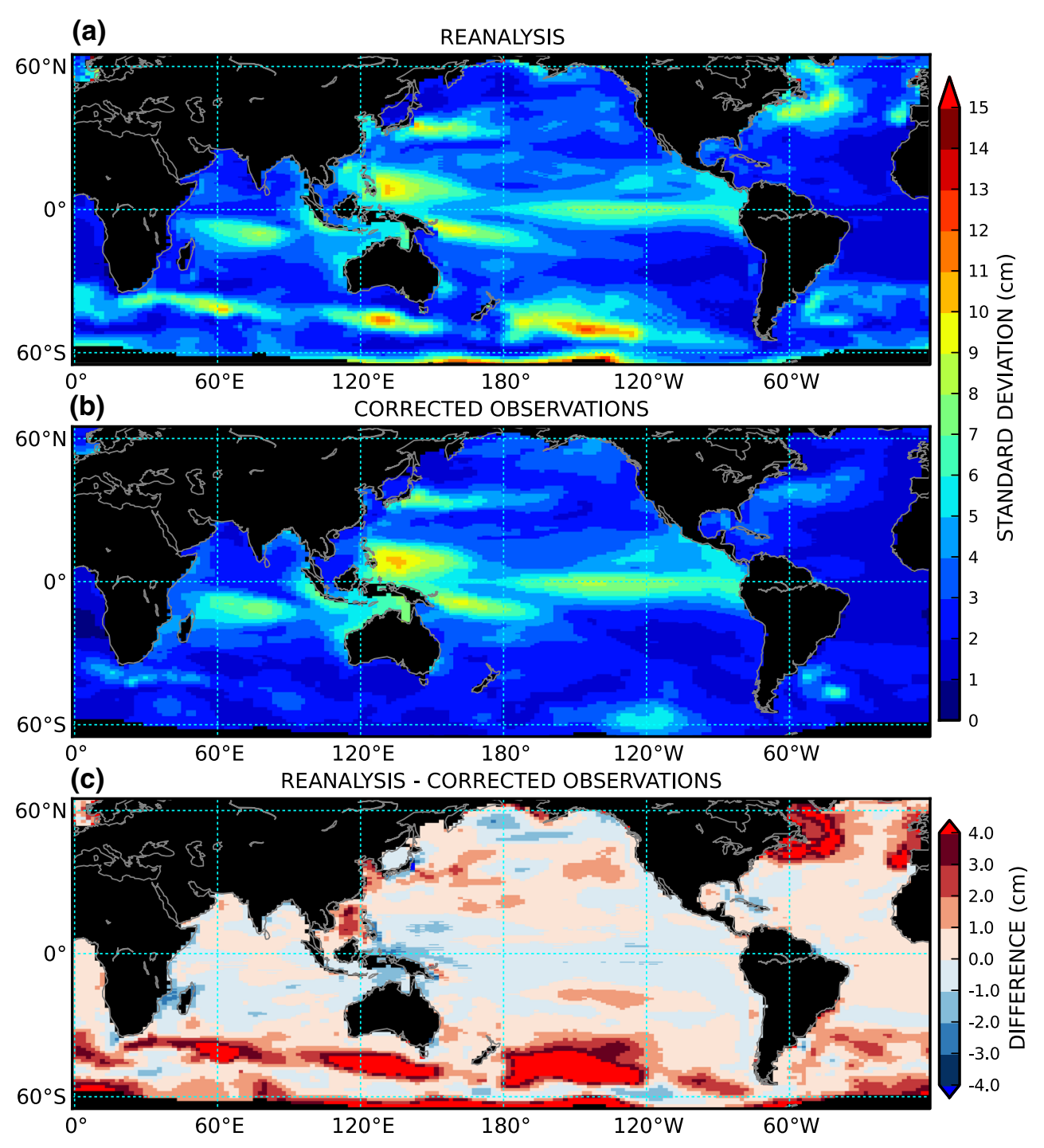

signals such as the PDO; and given the reanalysis has large variability in the Southern Ocean and north-west Atlantic which does not agree with the observations, the validated region will be restricted to latitudes between $40^{\circ} \mathrm{N}$ and $40^{\circ} \mathrm{S}$. Based on studies by O'Kane et al. (2013), it is likely that the exclusion of the Southern Ocean does not eliminate any real-world effects to seasonal scale signals in the analysis region.

\subsection{Model skill using the reanalysis}

Figure 3 shows the correlation of seasonal SLA between the reanalysis and forecasts based on persistence and the model forecasts for the austral summer at lead-times 0,3 and 6 months over the period 1981-2010. In addition, the upper limit of these correlations from the predictability calculation is shown. Figure 4 shows the same for austral winter. Note that if the ensemble spread is too narrow, and there is some evidence that this is the case for POAMA's rainfall predictions (Lim et al. 2009a), predictability will be an overestimate of model potential skill (Rashid et al. 2010; Wang et al. 2011). In general, the model skill is higher than that of persistence for all lead-times. Compared to model predictability, the model could be further improved in the Atlantic Ocean, South Indian Ocean and in the mid-latitudes of the Pacific Ocean.

To ensure that use of the PEODAS reanalysis is not unreasonably overestimating the model skill, the shorter 1993-2010 period was investigated using both reanalysis and altimeter observations. Model forecast skill was similar in the Pacific, central Atlantic Ocean and Indian Ocean for lead-times above 0 months (not shown). POAMA has larger regions of significant skill $(r>0.8)$ in the higher latitudes when validated with PEODAS at lead-time 0 months. However, the equatorial Pacific in particular shows little change at any lead-time above zero (not shown).

The area of highest skill for the austral summer seasons (December-January-February (DJF); Fig. 3) is the eastern 


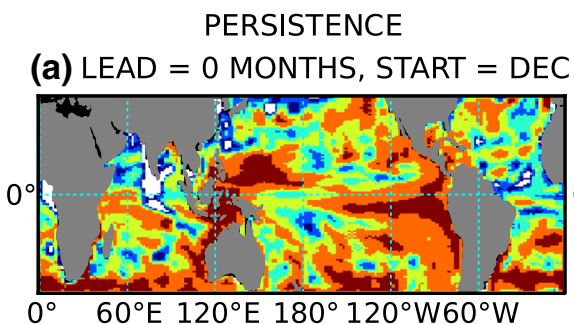

(d) LEAD = 3 MONTHS, START = SEP

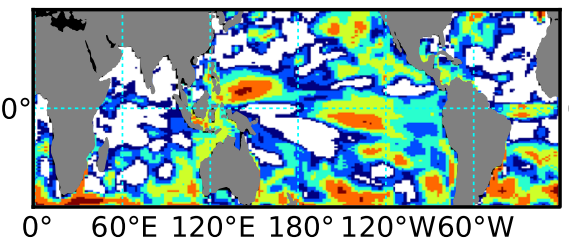

(g) LEAD $=6$ MONTHS, START $=$ JUN

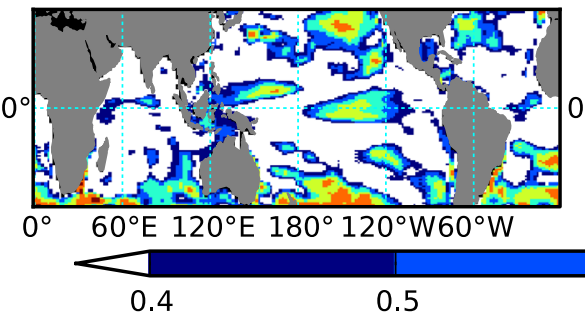

POAMA

(b) LEAD = 0 MONTHS, START = DEC

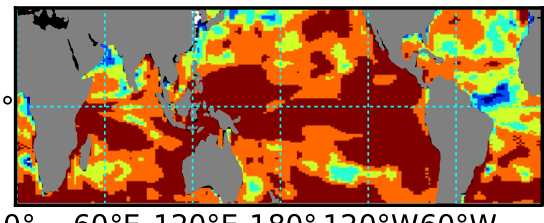

$60^{\circ} \mathrm{E} 120^{\circ} \mathrm{E} 180^{\circ} 120^{\circ} \mathrm{W} 60^{\circ} \mathrm{W}$
PREDICTABILITY

(c) LEAD = 0 MONTHS, START = DEC

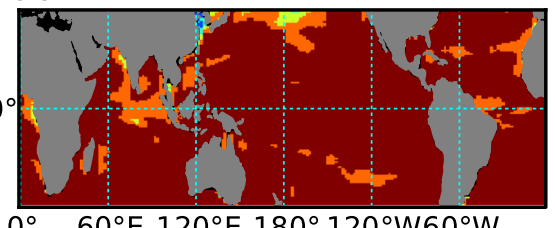

$0^{\circ} \quad 60^{\circ} \mathrm{E} 120^{\circ} \mathrm{E} 180^{\circ} 120^{\circ} \mathrm{W} 60^{\circ} \mathrm{W}$

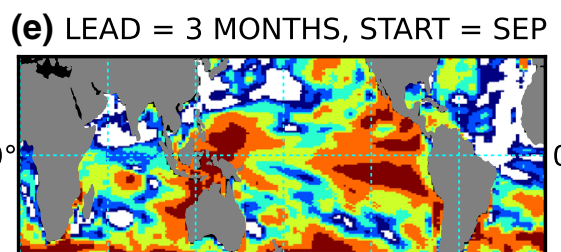

$0^{\circ} \quad 60^{\circ} \mathrm{E} 120^{\circ} \mathrm{E} 180^{\circ} 120^{\circ} \mathrm{W} 60^{\circ} \mathrm{W}$ (f) $L E A D=3$ MONTHS, START = SEP

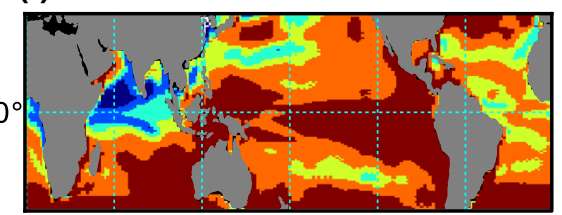

$0^{\circ} \quad 60^{\circ} \mathrm{E} 120^{\circ} \mathrm{E} 180^{\circ} 120^{\circ} \mathrm{W} 60^{\circ} \mathrm{W}$

(h) LEAD = 6 MONTHS, START = JUN

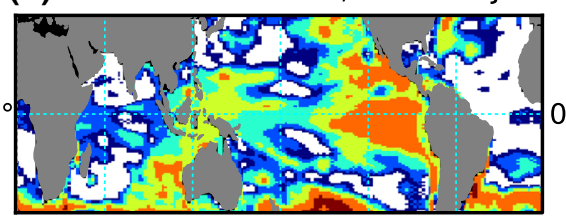

$0^{\circ} \quad 60^{\circ} \mathrm{E} 120^{\circ} \mathrm{E} 180^{\circ} 120^{\circ} \mathrm{W} 60^{\circ} \mathrm{W}$

(i) LEAD $=6$ MONTHS, START $=$ JUN

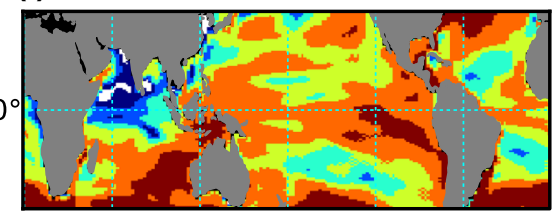

0.6

0.7

0.8

$0^{\circ} \quad 60^{\circ} \mathrm{E} 120^{\circ} \mathrm{E} 180^{\circ} 120^{\circ} \mathrm{W} 60^{\circ} \mathrm{W}$

CORRELATION

Fig. 3 Correlations of seasonal forecasts for SLA for target season DJF from 1981 to 2010 for (left column) persistence, (centre column) POAMA and (right column) model predictability against reanalyses

Pacific, where the model shows a high degree of skill in capturing the ENSO signal, though strong persistence skill is also evident. Model skill is higher than persistence in the Indian Ocean, particularly along the southern coast of India, the northern and equatorial Pacific, and around Indonesia. Predictability calculations indicate that increased skill may be possible in all of the ocean basins. However, POAMA does approach the predictability limit $(0.8<\mathrm{r}<1.0)$ in the western and eastern Pacific for all lead-times.

For the austral winter season (June-July-August (JJA), Fig. 4) there is again high model skill in the Pacific, particularly in the eastern region. Persistence skill is weaker than in the austral summer month (Fig. 3) with skill dropping below the significant level $(r>0.4)$ in the north Indian Ocean and west Pacific Ocean. Model skill remains higher than persistence in the equatorial Pacific and the Indian Ocean. The predictability limit decreases rapidly with lead-time in the south Atlantic, south Pacific and north Indian Ocean.

\subsection{Modes of sea level variance}

EOF analyses were performed over each season for both the PEODAS reanalysis and POAMA forecasts to for 0,3 and 6 months lead-times. Significant correlations are shaded ( $|r|>0.361$ is significant at the $95 \%$ confidence level; two-tailed $t$ test, $\mathrm{n}=30$, degrees of freedom determined by autocorrelation)

determine the leading modes of variance of seasonal SLA for lead-time 0. Figures 5 and 6 show the first three EOF spatial patterns and associated loading time series for seasons DJF and JJA respectively.

In both seasons, the POAMA EOF patterns and fractional contribution are very similar to PEODAS. During DJF, when ENSO is well established (Fig. 5), over half of the variance can be attributed to ENSO, with contributions from EOF2 and EOF3 almost an order of magnitude smaller. In JJA, the amount of variance explained by EOF1 and EOF2 is comparable, highlighting this season as a time of transition for ENSO, either alternating between the mature states or recharging (Fig. 6). The amount of variance explained and the spatial patterns of POAMA's EOF for DJF changes very little as lead-time increases (not shown). However, for JJA the amount of variance increases from $28.6 \%$ at lead-time 0 months to $45.4 \%$ at lead-time 6 months and the second EOF pattern develops a stronger cold tongue (not shown). These results confirm that the POAMA forecasts maintain the same dynamical features as in the observations and the analysis.

The IOD is also observed in EOF1 in Fig. 5. It is interesting to see that the IOD signal still has a strong sea level anomaly in DJF despite the fact that it disappears 
PERSISTENCE

(a) LEAD $=0$ MONTHS, START $=$ JUN

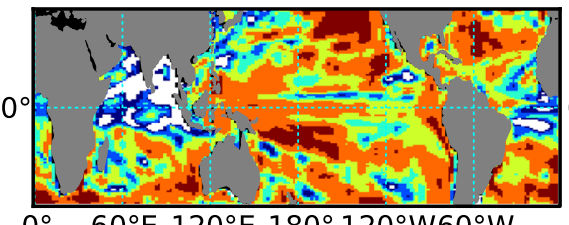

$0^{\circ} \quad 60^{\circ} \mathrm{E} 120^{\circ} \mathrm{E} 180^{\circ} 120^{\circ} \mathrm{W} 60^{\circ} \mathrm{W}$
POAMA

(b) LEAD $=0$ MONTHS, START $=$ JUN

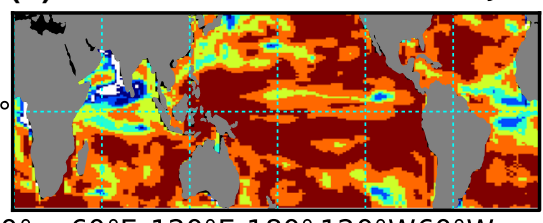

$0^{\circ} \quad 60^{\circ} \mathrm{E} 120^{\circ} \mathrm{E} 180^{\circ} 120^{\circ} \mathrm{W} 60^{\circ} \mathrm{W}$
PREDICTABILITY

(c) LEAD $=0$ MONTHS, START $=$ JUN

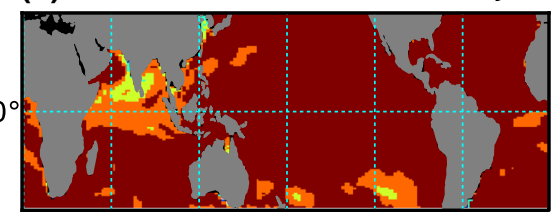

$0^{\circ} \quad 60^{\circ} \mathrm{E} 120^{\circ} \mathrm{E} 180^{\circ} 120^{\circ} \mathrm{W} 60^{\circ} \mathrm{W}$ (d) LEAD $=3$ MONTHS, START = MAR

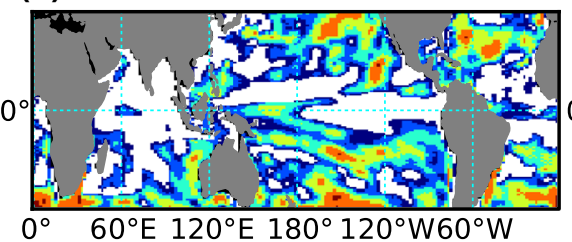

(e) LEAD $=3$ MONTHS, START $=$ MAR

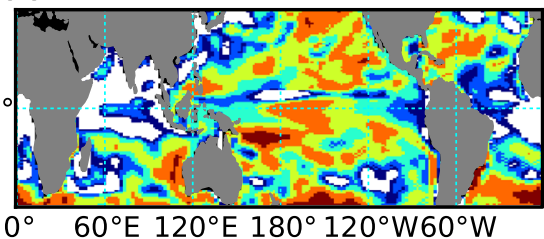

(f) $L E A D=3$ MONTHS, START = MAR

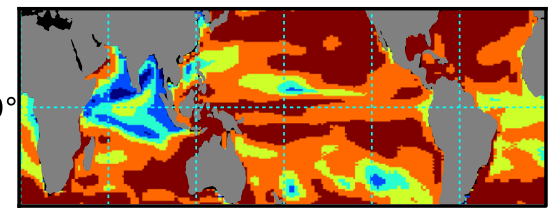

$0^{\circ} \quad 60^{\circ} \mathrm{E} 120^{\circ} \mathrm{E} 180^{\circ} 120^{\circ} \mathrm{W} 60^{\circ} \mathrm{W}$

(g) LEAD $=6$ MONTHS, START $=$ DEC

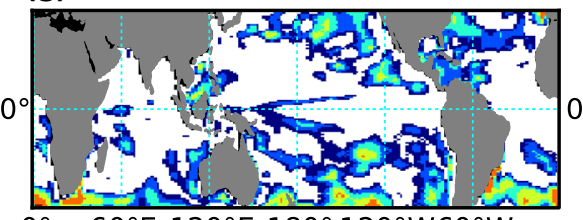

(h) LEAD $=6$ MONTHS, START $=$ DEC

(i) LEAD $=6$ MONTHS, START $=$ DEC

$0^{\circ} \quad 60^{\circ} \mathrm{E} 120^{\circ} \mathrm{E} 180^{\circ} 120^{\circ} \mathrm{W} 60^{\circ} \mathrm{W}$

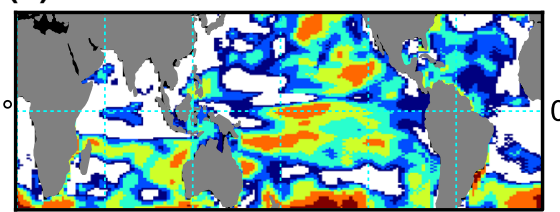

$\aleph_{0.4} 0.5$

$\begin{array}{ll}0.5 & 0.6\end{array}$

0.7

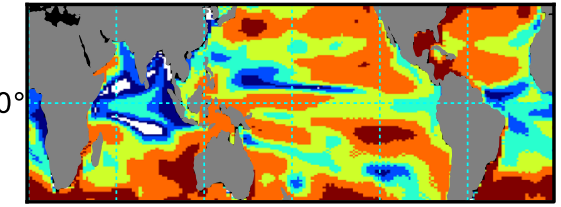

$60^{\circ} \mathrm{E} 120^{\circ} \mathrm{E} 180^{\circ} 120^{\circ} \mathrm{W} 60^{\circ} \mathrm{W}$

$0^{\circ} \quad 60^{\circ} \mathrm{E} 120^{\circ} \mathrm{E} 180^{\circ} 120^{\circ} \mathrm{W} 60^{\circ} \mathrm{W}$

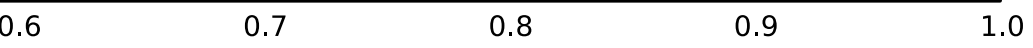

CORRELATION

Fig. 4 Same as for Fig. 3 but for JJA

(a) PC OF EOF1, $r=0.98$

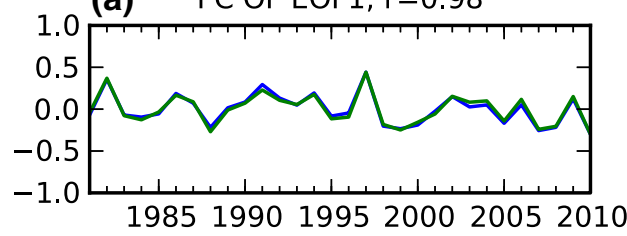

(d) PC OF EOF2, $r=0.95$

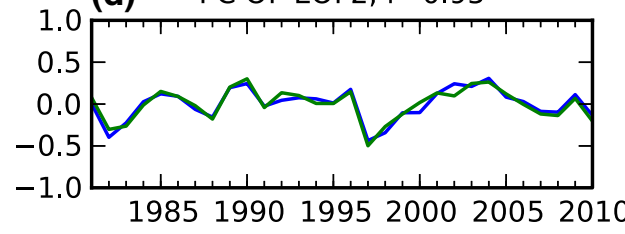

(g) PC OF EOF3, $r=0.94$

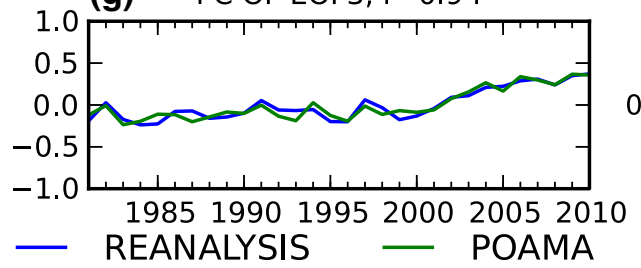

(b) REANALYSIS EOF1 - $51.5 \%$

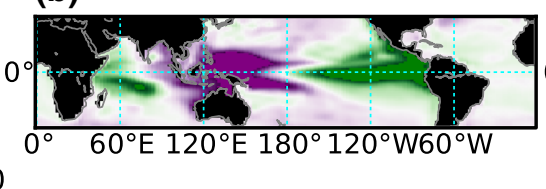

(e) REANALYSIS EOF2 - $8.7 \%$

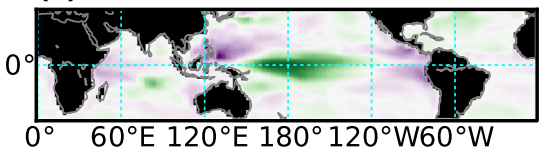

(h) REANALYSIS EOF3 - 7.3\%

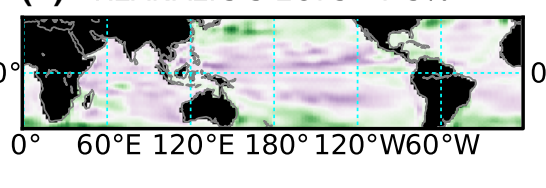

(i) POAMA EOF3 - $7.3 \%$

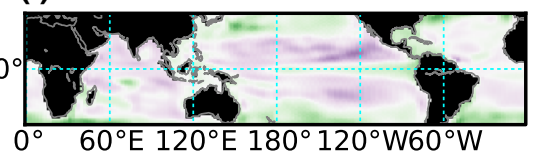

(c) POAMA EOF1 $-53.6 \%$

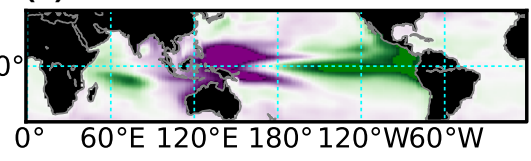

(f) POAMA EOF2 - $11.0 \%$

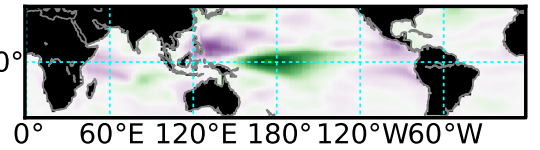

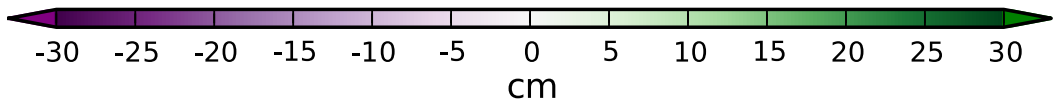

Fig. 5 EOF analysis of seasonal SLA targeting DJF. Plots a, $\mathbf{d}$ and $\mathbf{g}$ the loading time series of first three EOFs for the reanalysis (blue) and POAMA at 0 months lead-time (green). The first three EOFs of the reanalysis (b), (e) and (h) and POAMA at lead-time 0 months (c), (f) and (i) 
(a) PC OF EOF1, $r=0.97$

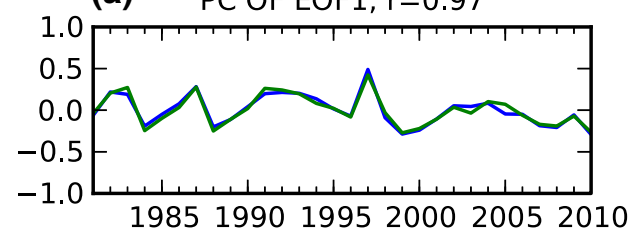

(d)

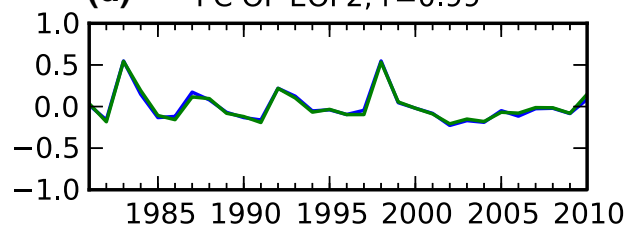

(g) PC OF EOF3, $r=0.88$

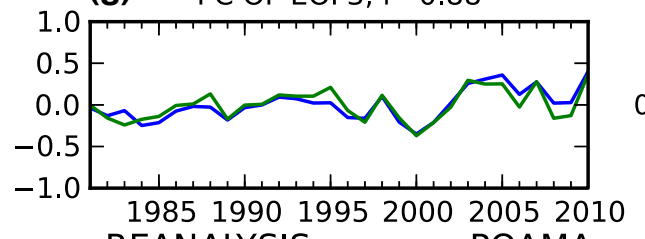

- REANALYSIS - POAMA (b) REANALYSIS EOF1 - $24.4 \%$

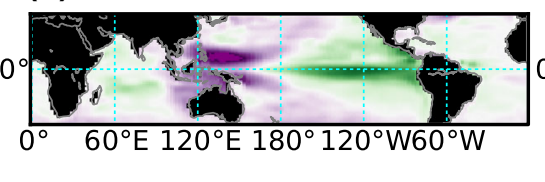

(c) POAMA EOF1 $-28.6 \%$

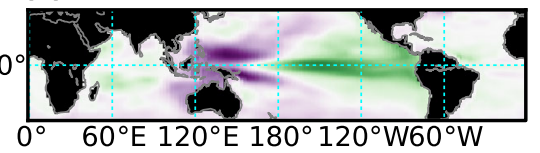

(e) REANALYSIS EOF2 - $20.0 \%$

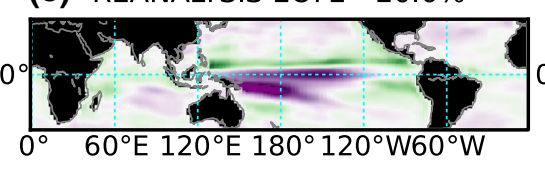

(f) POAMA EOF2 - $19.9 \%$

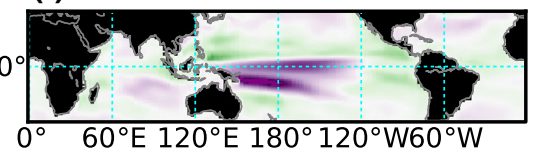

(h) REANALYSIS EOF3 - 10.1\%

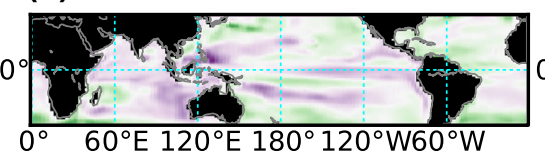

(i) POAMA EOF3 - $10.4 \%$

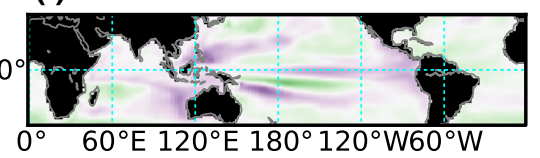

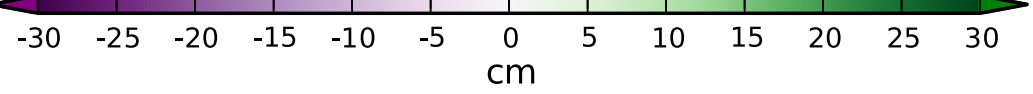

Fig. 6 Same as for Fig. 5 but for JJA

from the SST in December (Saji et al. 1999; Hendon et al. 2012). Whilst the IOD covaries strongly with ENSO in austral spring (Lim et al. 2009b; Cai et al. 2011) and rapidly terminates as the Australian monsoon develops in the austral early summer season (Hendon et al. 2012), it evidently still persists in the subsurface, affecting the SLA at the eastern and western boundaries of the Indian Ocean. In addition, EOF1 has a strong signature of a variable strength Leeuwin current along the West Australian coastline associated with ENSO. This contributes to the forecast skill of SLA in this region (see Figs. 3, 4). The Atlantic Ocean shows very little variability for both seasons. This analysis was also performed using the altimeter observations and yielded similar fields and loadings (not shown).

\subsection{Mature ENSO events}

Given that both the reanalysis and model represent ENSO well (based on the EOF analysis), we investigate the relationship between high SSTA and SLA. The listed ENSO events are consistent with those of NOAA's 3-month running average of NINO3 using their Extended Reconstructed SST and a 1971-2000 climatology (NOAA). It should be noted that this method could possibly alias longer climate variability modes in the composites such as the PDO given the short time period this analysis is conducted over.

The amplitudes of SSTA during the mature phase of El Niño are generally larger than that of La Niña. Using the identified periods in Table 2, composites of seasonal SLAs for the mature phases of El Niño and La Niño during 1981-2010 for the reanalysis and POAMA for lead-times 0,3 and 6 months are created by averaging the seasonal SLA on these dates with equal weighting (see Fig. 7).

The composites generated by the reanalysis (Fig. 7a, b) show the asymmetric characteristic of SLA in the tropics during ENSO events, and agree well with previous studies (Nerem et al. 1999; Kang and Kug 2002). Comparison between Fig. 7a, b indicate that the observed SLA associated with El Niño are a little stronger and shifted about $15^{\circ}$ to the east compared to those of La Niña. The asymmetric SLA pattern generated by PEODAS for the two ENSO states reflects similar findings from Kang and Kug (2002) and Dommenget et al. (2012).

The model prediction composites Fig. 7c-h indicate that POAMA can capture the spatial structure of seasonal SLA during mature ENSO events relatively accurately. However a slight overextension of the local maxima of the cold tongue $15^{\circ}$ westward is evident, as similarly shown for SST prediction by POAMA in earlier studies (Hendon et al. 2009). POAMA under predicts the amplitude of seasonal SLA relative to the reanalysis at all lead-times, increasing with lead-time. This is a common trait of anomaly predictions created by ensemble prediction models. As leadtime increases so too does the spread of the ensemble, whilst the skill of each individual ensemble member decreases. The net effect is the mean anomaly value approaches zero i.e. climatology (Peng et al. 2009). 
Fig. 7 Composites of seasonal SLA for the mature phases of $\mathrm{El}$ Niño and La Niña. Six El Niño and La Niña events between the years 1981-2010 are used in the composites. a, b Correspond to observed SLA from the reanalysis and $\mathbf{c}-$

h the forecasted seasonal SLA using the POAMA model at lead-times 0,3 and 6 months
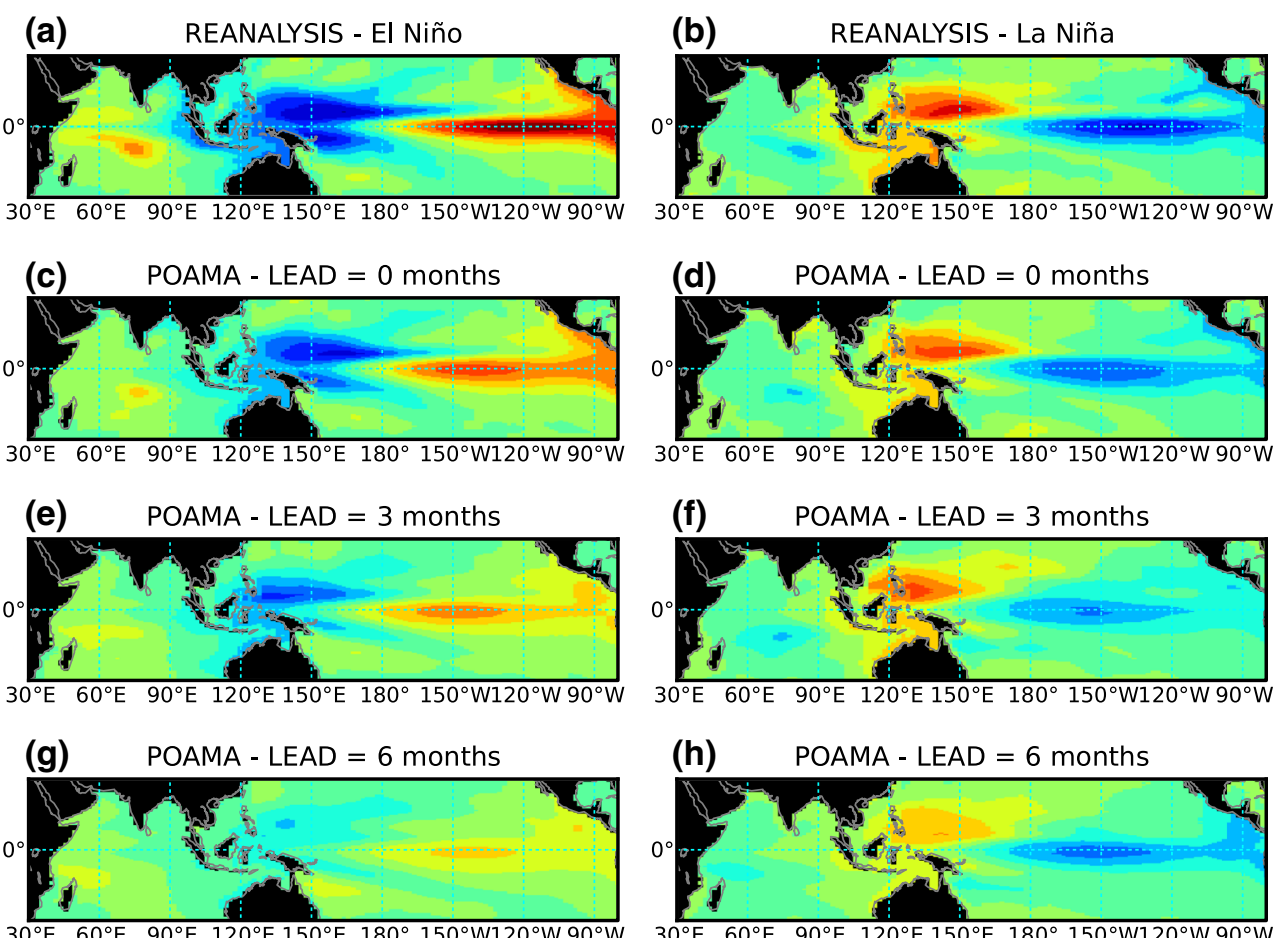

(h) POAMA - LEAD $=6$ months
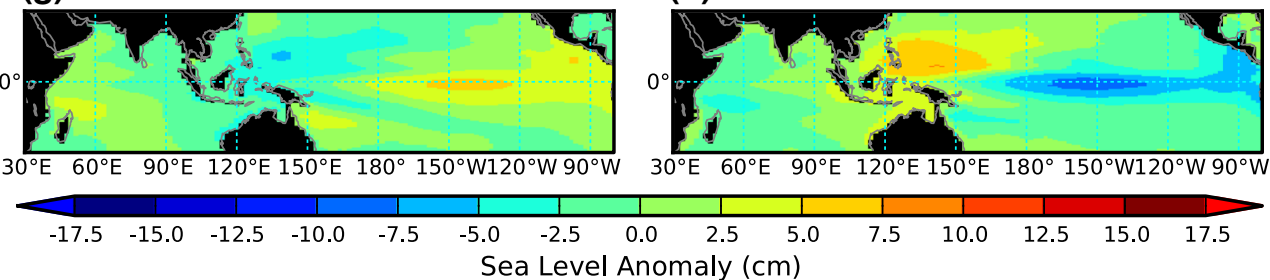

Nevertheless, the overall spatial patterns during El Niño/La Niña events are well predicted by POAMA, including associated IOD and Leeuwin current signals. The SLA in the Indian ocean is attributed to anomalies in the easterly winds and the associated oceanic Kelvin and Rossby waves (Vinayachandran et al. 2007).

\section{Discussion}

In this paper, we present an initial attempt (the first to our knowledge) to investigate the skill of seasonal SLA forecasts created by the dynamical coupled ocean-atmosphere multi-model ensemble global system POAMA. This assessment was conducted using corrected altimeter observations and model reanalysis. Note that the model does not assimilate either altimeter or tide-gauge observations. We have identified the capabilities and deficiencies of POAMA in predicting SLA which will underpin the validity of real-time forecasts.

As the altimetry period only covers 18 years (1993-2010), the reanalysis PEODAS was used to evaluate POAMA. The model reanalysis of seasonal SLA was demonstrated to have significant correlations (95\% confidence $|r|>0.46)$ with altimeter observations. As the reanalysis does not assimilate altimeter observations, this result demonstrates that temperature and salinity observations are sufficient to capture the baroclinic and barotropic circulation, and the advection and dissipation components of seasonal SLAs. However, the reanalysis exhibits larger variability in the higher latitudes than the altimeter observations, caused by the spurious trends and signals in salinity and/or temperature values due to the non-stationary nature of the observing system coupled with model bias. This is a common problem for most ocean data assimilation systems (Yin et al. 2011). EOF analysis showed that the first two modes of seasonal SLA in both the reanalysis (Figs. 5, 6) and observations (not shown) are dominated by ENSO and the IOD. It should be noted that this study does not seek to resolve lower frequency components of signals such as the PDO or NAO which also influence global and local sea levels (Zhang and Church 2012).

Using the reanalysis over a 30 year period (1981-2010), POAMA SLA forecasts are shown to have statistically significant correlations at lead-times of up to 7 months for both winter and summer seasons in the Pacific basin. Model-based predictability estimates suggest improvements can be made at lead-times beyond 3 months in the Indian and north Atlantic Oceans. The skill is greatest in the equatorial Pacific basin, with high skill near the west coast of north and south America and the west coast of 
Australia, during DJF and is a result of the strength and predictability of ENSO, which delivers the dominant SLA seasonal signal at both the global-mean and regional scale. A known weakness of POAMA is its inability to accurately predict the IOD beyond 4 months (Zhao and Hendon 2009). However, predictability studies indicate this region could have useful skill at the 6 month lead-time (Zhao and Hendon 2009; Shi et al. 2012). Previous studies by Xue and Leetmaa (2000) using a Markov model have shown that sea level is more predictable than SST in the western Pacific. It is speculated that SLA associated with the IOD may have more predictability than SSTA as the sea level filters the response of the ocean to high-frequency wind forcing (Xue et al. 2000). Model improvements to achieve this include an increase in model resolution and better modelling of the upwelling processes in the Java-Sumatra coast, both of which would have implications for SSH in this region. SLA skill in the Atlantic Ocean is limited to 1-2 months and is no more skilful than persistence, a result consistent with many other contemporary dynamical forecast systems (Stockdale 1997). It has been suggested that this limitation stems from a combination of model error (especially bias in simulating the mean SST state), deficient ocean initial conditions, and the relatively weak role of (slow) subsurface variations which can influence SSH calculations. Whilst model predictability studies indicate that further decreases in model error may lead to more skilful forecasts at longer lead-times in the north Atlantic Ocean and Indian Ocean, POAMA's skill is greater than that of persistence in the Pacific and Indian oceans, indicating these forecasts have useful skill on a seasonal timescale.

EOF analysis was performed to demonstrate that POAMA's skill in the Pacific region can be attributed to its ability to accurately model ENSO events. The EOF results show that for all seasons it is the ENSO signal and its associated recharging/discharging phases that dominate the SLA variance. Prior to an ENSO event, heat content anomalies begin to accrue in the upper layers of the ocean, and are directly reflected by SLA via thermosteric sea level. During ENSO discharge and recharging phases this heat, and by association SLA, is transported across the Pacific via Kelvin and Rossby waves along the equator (Wang and Picaut 2004; Wang and Fiedler 2006). The IOD may also play a similar role in the Indian Ocean. In DJF, peak ENSO season, the ENSO signal contributes over half of the variance whilst in JJA the variance contributions between ENSO mature and transition patterns are comparable. As lead-time increases, the variance in POAMA forecasts decrease relative to the reanalysis but maintains the overall spatial pattern (not shown). Composites during mature ENSO phases show that the characteristic SLA ENSO pattern is well captured, despite a shift in the cold tongue and dampening of amplitude relative to the reanalysis. Teleconnections with the NINO3 index at various lags (not shown) indicate that the skill in the equatorial Pacific and Indian Ocean is derived from POAMA's ability to model equatorial waves and by association ENSO and the IOD. The IPCC reports there may be a weak shift towards an 'El Niño-like' background condition under climate change but the fundamental processes will continue (Meehl et al. 2007), so POAMA is expected to provide useful forecasts into the future. A paper that compares the skill of POAMA performance relative to statistical models and in situ tide gauge measurements is being prepared.

There exists a variety of regional processes that influence and contribute to the heterogeneity of SLA patterns across the globe, including GIA, ground water storage, mean sea level pressure and ice-melt. However on the seasonal time-scale, these contributions are second order relative to the magnitude of the ocean-atmosphere response. The application of regional downscaling of model forecasts to sub-grid scales has the potential to increase the value of the model for coastal and island locations not adequately resolved due to POAMA's coarse grid.

These results demonstrate the skill of POAMA's global predictions of seasonal SLA, indicating that they can be used to fill the current gap in seamless SLA prediction at all time scales and at a broader range of locations than served by present statistical forecasts based on a small number of historical tide gauge records. As a result these forecasts may be a very effective tool for coastal communities and policy makers. This research underpins a real-time sea level prediction system for $40^{\circ} \mathrm{N}-40^{\circ} \mathrm{S}$ based on POAMA which has been deployed by the Bureau of Meteorology under the PACCSAP program. Ensemble forecasts of SLA are issued weekly and are available online in real time as an experimental product (http://www.bom.gov.au/climate/ pacific/about-sea-level-outlooks.shtml, Miles et al. 2013). Products include spatial SLA predictions, probabilistic forecasts for extreme SLA events and country specific indices. We hope the availability of this information will underpin improved management of extreme sea level events, particularly in view of the likely increase in their frequency and severity as a consequence of global warming.

Acknowledgments This research contributes to the Pacific Australia Climate Change Science and Adaptation Program (PACCSAP) funded by AusAID and the Department of Climate Change and Energy Efficiency and delivered by the Bureau of Meteorology and CSIRO. We acknowledge CNES (France) and NASA (USA) for their roles in the TOPEX/Poseidon and Jason-1 missions and for making the data freely available. We also acknowledge CNES, NASA, NOAA (USA) and EUMETSAT (Europe) for their roles in the Jason2/OSTM mission and for making the data freely available. We thank Dr Eunpa Lim, Dr Andy Taylor and Dr Debra Hudson for reviewing 
this paper, Griffith Young, Dr Guomin Wang and Faina Tseitkin for hindcast preparation, Dr Yonghong Yin for the PEODAS reanalyses and Dr Neil White for the observation based sea level analyses.

Open Access This article is distributed under the terms of the Creative Commons Attribution License which permits any use, distribution, and reproduction in any medium, provided the original author(s) and the source are credited.

\section{References}

Becker M, Meyssignac B, Letetrel C et al (2012) Sea level variations at tropical Pacific islands since 1950. Glob Planet Chang 80-81:85-98. doi:10.1016/j.gloplacha.2011.09.004

Benada JR (1997) PO.DAAC Merged GDR (TOPEX/POSEIDON) Generation B User's Handbook, Version 2.0. JPL PO.DAAC D-11007. Jet Propulsion Laboratory, California Institute of Technology, Pasadena, p 124

Boening C, Willis JK, Landerer FW et al (2012) The 2011 La Niña: so strong, the oceans fell. Geophys Res Lett 39:n/a-n/a. doi:10. 1029/2012GL053055

Brassington GB, Freeman J, Huang X et al (2012) Ocean model, analysis and prediction system: version 2. CAWCR Tech Rep $52: 103$

Bryan K (1969) A numerical method for the study of the circulation of the world ocean. J Comput Phys 4:347-376. doi:10.1016/ 0021-9991(69)90004-7

Cai W, van Rensch P, Cowan T, Hendon HH (2011) Teleconnection Pathways of ENSO and the IOD and the Mechanisms for Impacts on Australian Rainfall. J Clim 24:3910-3923. doi:10. 1175/2011JCLI4129.1

Chambers DP, Wahr J, Nerem RS (2004) Preliminary observations of global ocean mass variations with GRACE. Geophys Res Lett 31:1-4. doi:10.1029/2004GL020461

Chen D, Rothstein LM, Busalacchi AJ (1994) A Hybrid Vertical Mixing Scheme and Its Application to Tropical Ocean Models. J Phys Oceanogr 24:2156-2179. doi:10.1175/1520-0485(1994) 024<2156:AHVMSA > 2.0.CO;2

Chen JL, Wilson CR, Chambers DP et al (1998) Seasonal global water mass budget and mean sea level variations. Geophys Res Lett 25:3555-3558. doi:10.1029/98GL02754

Chowdhury MR, Chu P, Schroeder T, Colasacco N (2007) Seasonal sea-level forecasts by canonical correlation analysis-an operational scheme for the U.S.-affiliated Pacific Islands. Int J Climatol 27:1389-1402. doi:10.1002/joc.1474

Church JA, White NJ (2011) Sea-Level Rise from the Late 19th to the Early 21st Century. Surv Geophys 32:585-602. doi:10.1007/ s10712-011-9119-1

Church JA, White NJ, Coleman R et al (2004) Estimates of the Regional Distribution of Sea Level Rise over the 1950-2000 Period. J Clim 17:2609-2625. doi:10.1175/1520-0442(2004) 017<2609:EOTRDO>2.0.CO;2

Church JA, Hunter JR, Mcinnes KL, White NJ (2006a) Sea-level rise around the Australian coastline and the changing frequency of extreme sea-level events. Aust Meteorol Mag 55:253-260

Church JA, White NJ, Hunter JR (2006b) Sea-level rise at tropical Pacific and Indian Ocean islands. Glob Planet Chang 53:155-168. doi:10.1016/j.gloplacha.2006.04.001

Church JA, Clark PU, Cazenave A et al (2014) Sea level change. In: Stocker TF, Qin D, Plattner G-K et al (eds) Climate change 2014: the physical science basis. Contribution of working group I to the fifth assessment report of the intergovernmental panel on climate change. Cambridge University Press, Cambridge
Colman R, Deschamps L, Naughton M et al (2005) BMRC atmospheric model (BAM) version 3.0: comparison with mean climatology. BMRC Res Rep 108:66

Dommenget D, Bayr T, Frauen C (2012) Analysis of the non-linearity in the pattern and time evolution of El Niño southern oscillation. Clim Dyn 40:2825-2847. doi:10.1007/s00382-012-1475-0

Drévillon M, Bourdallé-Badie R, Derval C et al (2008) The GODAE/ Mercator-Ocean global ocean forecasting system: results, applications and prospects. J Oper Oceanogr 1:51-57

Gregory JM, White NJ, Church JA et al (2013) Twentieth-century global-mean sea level rise: is the whole greater than the sum of the parts? J Clim 26:4476-4499. doi:10.1175/JCLI-D-1200319.1

Griffies SM, Bryan K (1997) A predictability study of simulated North Atlantic multidecadal variability. Clim Dyn 13:459-487. doi: $10.1007 / \mathrm{s} 003820050177$

Hendon HH, Lim E-P, Wang G et al (2009) Prospects for predicting two flavors of El Niño. Geophys Res Lett 36:L19713. doi:10. 1029/2009GL040100

Hendon HH, Lim E-P, Liu G (2012) The Role of Air-Sea Interaction for Prediction of Australian Summer Monsoon Rainfall. J Clim 25:1278-1290. doi:10.1175/JCLI-D-11-00125.1

Hudson D, Alves O, Hendon HH, Wang G (2010) The impact of atmospheric initialisation on seasonal prediction of tropical Pacific SST. Clim Dyn 36:1155-1171. doi:10.1007/s00382-0100763-9

Hudson D, Marshall AG, Yin Y et al (2013) Improving Intraseasonal Prediction with a New Ensemble Generation Strategy. Mon Weather Rev 141:4429-4449. doi:10.1175/MWR-D-13-00059.1

Kang I-S, Kug J-S (2002) El Niño and La Niña sea surface temperature anomalies: asymmetry characteristics associated with their wind stress anomalies. J Geophys Res 107:4372. doi:10.1029/2001JD000393

Keihm SJ, Zlotnicki V, Ruf CS (2000) TOPEX microwave radiometer performance evaluation, 1992-1998. IEEE Trans Geosci Remote Sens 38:1379-1386. doi:10.1109/36.843032

Kistler R, Collins W, Saha S et al (2001) The NCEP-NCAR 50-year reanalysis: monthly means CD-ROM and documentation. Bull Am Meteorol Soc 82:247-267. doi:10.1175/1520-0477(2001) $082<0247$ :TNNYRM $>2.3 . \mathrm{CO} ; 2$

Landerer FW, Jungclaus JH, Marotzke J (2008) El Niño-Southern Oscillation signals in sea level, surface mass redistribution, and degree-two geoid coefficients. J Geophys Res 113:C08014. doi:10.1029/2008JC004767

Lim E-P, Hendon HH, Alves O et al (2009a) Impact of SST bias correction on prediction of ENSO and Australian winter rainfall. CAWCR Res Lett 3:1-7

Lim E-P, Hendon HH, Hudson D et al (2009b) Dynamical Forecast of Inter-El Niño Variations of Tropical SST and Australian Spring Rainfall. Mon Weather Rev 137:3796-3810. doi:10.1175/ 2009MWR2904.1

Lombard A, Cazenave A, Letraon P, Ishii M (2005) Contribution of thermal expansion to present-day sea-level change revisited. Glob Planet Chang 47:1-16. doi:10.1016/j.gloplacha.2004.11. 016

Lombard A, Garcia D, Ramillien G et al (2007) Estimation of steric sea level variations from combined GRACE and Jason-1 data. Earth Planet Sci Lett 254:194-202. doi:10.1016/j.epsl.2006.11. 035

Manabe S, Holloway JL (1975) The seasonal variation of the hydrologic cycle as simulated by a global model of the atmosphere. J Geophys Res 80:1617-1649. doi:10.1029/ JC080i012p01617

McGranahan G, Balk D, Anderson B (2007) The rising tide: assessing the risks of climate change and human settlements in low 
elevation coastal zones. Environ Urban 19:17-37. doi:10.1177/ 0956247807076960

McInnes KL, Macadam I, Hubbert GD, O'Grady JG (2009) A modelling approach for estimating the frequency of sea level extremes and the impact of climate change in southeast Australia. Nat Hazards 51:115-137. doi:10.1007/s11069-0099383-2

Meehl GA, Stocker TF, Collins WD et al (2007) Global climate projections. In: Solomon S, Qin D, Manning M et al (eds) Climate change 2007: the physical science basis. Contribution of working group I to the fourth assessment report of the intergovernmental panel on climate change. Cambridge University Press, Cambridge, New York, pp 747-845

Menendez M, Mendez FJ, Losada IJ (2009) Forecasting seasonal to interannual variability in extreme sea levels. ICES J Mar Sci 66:1490-1496. doi:10.1093/icesjms/fsp095

Miles E, Spillman C, McIntosh PC et al (2013) Seasonal sea-level predictions for the Western Pacific. 20th International Congress Model Simulation, Adelaide, Australia, 1-6 Dec 2013

Minster JF, Cazenave A, Serafini YV et al (1999) Annual cycle in mean sea level from Topex-Poseidon and ERS-1: inference on the global hydrological cycle. Glob Planet Chang 20:57-66. doi:10.1016/S0921-8181(98)00058-7

Mitchum GT (1998) Monitoring the Stability of Satellite Altimeters with Tide Gauges. J Atmos Ocean Technol 15:721-730. doi:10. 1175/1520-0426(1998)015<0721:MTSOSA > 2.0.CO;2

Mitchum GT (2000) An Improved Calibration of Satellite Altimetric Heights Using Tide Gauge Sea Levels with Adjustment for Land Motion. Mar Geod 23:145-166. doi:10.1080/014904100501 28591

Mitrovica JX, Milne GA, Davis JL (2001) Glacial isostatic adjustment on a rotating earth. Geophys J Int 147:562-578. doi:10.1046/j. 1365-246x.2001.01550.x

Nerem RS, Chambers DP, Leuliette EW et al (1999) Variations in global mean sea level associated with the 1997-1998 ENSO event: implications for measuring long term sea level change. Geophys Res Lett 26:3005-3008. doi:10.1029/1999GL002311

Nicholls RJ, Wong PP, Burkett VR et al (2007) Coastal systems and low-lying areas. In: Parry ML, Canziani OF, Palutikof JP et al (eds) Climate change 2007: impacts, adaptation and vulnerability. Contribution of working group II to the fourth assessment report of the intergovernmental panel on climate change. Cambridge University Press, Cambridge, pp 315-356

NOAA Climate Prediction Center-Monitoring Data: Current Monthly Atmospheric and Sea Surface Temperatures Index Values. http://www.cpc.ncep.noaa.gov/data/indices/. Accessed 19 Jun 2012

O'Kane TJ, Matear RJ, Chamberlain MA et al (2013) Decadal variability in an OGCM Southern Ocean: intrinsic modes, forced modes and metastable states. Ocean Model 69:1-21. doi:10. 1016/j.ocemod.2013.04.009

Oke PR, Schiller A, Griffin DA, Brassington GB (2005) Ensemble data assimilation for an eddy-resolving ocean model of the Australian region. Q J R Meteorol Soc 131:3301-3311. doi:10. 1256/qj.05.95

Pacanowski RC (1996) MOM2: documentation, user's guide and reference manual. GFDL Ocean Tech Rep 3(2):329

Peng P, Kumar A, Wang W (2009) An analysis of seasonal predictability in coupled model forecasts. Clim Dyn 36:637648. doi:10.1007/s00382-009-0711-8

Ponte RM (2006) Low-frequency sea level variability and the inverted barometer effect. J Atmos Ocean Technol 23:619-629. doi:10.1175/JTECH1864.1

Rashid HA, Hendon HH, Wheeler MC, Alves O (2010) Prediction of the Madden-Julian oscillation with the POAMA dynamical prediction system. Clim Dyn 36:649-661. doi:10.1007/s00382010-0754-x

Reynolds RW, Rayner NA, Smith TM et al (2002) An improved in situ and satellite SST analysis for climate. J Clim 15: 1609-1625. doi:10.1175/1520-0442(2002)015<1609:AIISAS> 2.0.CO;2

Saji NH, Goswami BN, Vinayachandran PN, Yamagata T (1999) A dipole mode in the tropical Indian Ocean. Nature 401:360-363. doi: $10.1038 / 43854$

Schiller A, Godfrey JS, McIntosh PC et al (2002) A new version of the Australian community ocean model for seasonal climate prediction. CSIRO Mar Lab Rep Ser 240:79

Shi L, Hendon HH, Alves O et al (2012) How predictable is the Indian Ocean dipole? Mon Weather Rev 140:3867-3884. doi:10. 1175/MWR-D-12-00001.1

Spillman CM, Alves O, Hudson DA (2013) Predicting thermal stress for coral bleaching in the Great Barrier Reef using a coupled ocean-atmosphere seasonal forecast model. Int $\mathrm{J}$ Climatol 33:1001-1014. doi:10.1002/joc.3486

Stockdale TN (1997) Coupled ocean-atmosphere forecasts in the presence of climate drift. Mon Weather Rev 125:809-818. doi:10.1175/1520-0493(1997)125<0809:COAFIT > 2.0.CO;2

Troccoli A, Harrison M, Anderson DLT, Mason SJ (2008) Seasonal climate: forecasting and managing risk. NATO science series, vol 82. Springer Academic Publishers, Dordrecht

Uppala SM, KÅllberg PW, Simmons AJ et al (2005) The ERA-40 reanalysis. Q J R Meteorol Soc 131:2961-3012. doi:10.1256/qj.04.176

Valcke S, Terray L, Piacentini A (2000) Oasis 2.4, ocean atmosphere sea ice soil: user's guide. CERFACS TR/CMGC/00-10

Vinayachandran PN, Kurian J, Neema CP (2007) Indian Ocean response to anomalous conditions in 2006. Geophys Res Lett 34:L15602. doi:10.1029/2007GL030194

Wang C, Fiedler PC (2006) ENSO variability and the eastern tropical Pacific: a review. Prog Oceanogr 69:239-266. doi:10.1016/j. pocean.2006.03.004

Wang C, Picaut J (2004) Understanding ENSO physics—a review. In: Wang C, Xie S-P, Carton JA (eds) Earth's climate: the oceanatmosphere interaction, geophysical monograph series, vol 147. American Geophysical Union, Washington, pp 21-48

Wang G, Alves O, Smith NR (2005) BAM3.0 tropical surface flux simulation and its impact on SST drift in a coupled model. BMRC Res Rep 107:30

Wang G, Alves O, Hudson D et al (2008) SST skill assessment from the new POAMA-1.5 system. BMRC Res Lett 8:1-6

Wang G, Hudson DA, Yin Y et al (2011) POAMA-2 SST skill assessment and beyond. CAWCR Res Lett 6:40-46

Webb DDJ (1988) Tides, surges and mean sea-level. Mar Pet Geol 5:301. doi:10.1016/0264-8172(88)90013-X

Wilks DS (1995) Statistical methods in the atmospheric sciences, 1st edn. Academic Press, London

Willis JK, Chambers DP, Nerem RS (2008) Assessing the globally averaged sea level budget on seasonal to interannual timescales. J Geophys Res 113:C06015. doi:10.1029/2007JC004517

Xue Y, Leetmaa A (2000) Forecasts of tropical Pacific SST and sea level using a Markov model. Geophys Res Lett 27:2701-2704. doi:10.1029/1999GL011107

Xue Y, Leetmaa A, Ji M (2000) ENSO prediction with Markoy models: the impact of sea level. J Clim 13:849-871. doi:10.1175/ 1520-0442(2000)013<0849:EPWMMT>2.0.CO;2

Yin Y, Alves O, Oke PR (2011) An ensemble ocean data assimilation system for seasonal prediction. Mon Weather Rev 139:786-808. doi:10.1175/2010MWR3419.1

Zhang X, Church JA (2012) Sea level trends, interannual and decadal variability in the Pacific Ocean. Geophys Res Lett. doi:10.1029/ 2012GL053240 
Zhao M, Hendon HH (2009) Representation and prediction of the Indian Ocean dipole in the POAMA seasonal forecast model. Q J R Meteorol Soc 135:337-352. doi:10.1002/qj.370
Zhong A, Alves O, Hendon HH, Rikus L (2006) On aspects of the mean climatology and tropical interannual variability in the BMRC atmospheric model (BAM 3.0). BMRC Res Rep 121:34 